\title{
Starch granules as markers of diet and behavior
}

Amanda G. Henry

HARVEST project, Faculty of Archaeology, Leiden University, Einsteinweg 2, 2333CC Leiden, The Netherlands

a.g.henry@arch.leidenuniv.nl

\section{Abstract}

Starch granules, the energy-storage molecules produced by plants, are increasingly used in archaeological studies as markers of human diet and food processing. While starch granules are organic in nature, their semi-crystalline structure likely contributes to their preservation in some protected archaeological contexts, such as within dental calculus or pottery crusts. Many naturally-occurring and human-induced processes can damage or destroy starches, however, so a detailed understanding of how starches are formed and ultimately preserved is necessary to accurately translate the starch record into meaningful statements about human behavior.

\section{Keywords}

Starch grain; starch granule; microfossil; archaeology; diet reconstruction; behavior reconstruction

\section{Starch granule formation}

Many different kinds of plants produce starch granules, including lower plants (mosses, ferns, etc.) and higher plants. Most starch is produced directly in the chloroplasts as a means of immediate energy storage, to be used during the night or at other times when energy is needed (BeMiller and Whistler 2009). These short-term starches are called transient starches, and are of limited use in archaeological analysis because of their very small size and lack of diagnostic features (Haslam 2004). Higher plants have specialized organelles, called amyloplasts, in which they produce larger 'storage' starches for long-term energy storage (Sivak and Preiss 1998). These starches are often produced in 
those parts of plants that require energy other than that created by photosynthesis after a long period of inactivity, such as underground storage organs (e.g., tubers, corms, and bulbs), seeds, and fruits.

While the formation of starches is broadly similar among all plants, details of the process differ among taxa. Many of these details are under genetic control, and give rise to the variation that allows us to identify the taxonomic origin of many starches. In simple terms, plants produce carbon sugars during photosynthesis, which are transferred to the amyloplasts and converted into two kinds of polysaccharides - amylose and amylopectin. Amylose is a straight-chained molecule and accounts for roughly $20-35 \%$ of the mass of the starch, though this amount can range from less than $15 \%$ to greater than $40 \%$ depending on the plant species or breed (BeMiller and Whistler 2009). Amylopectin is a heavily branched molecule and makes up the backbone of the starch. These polysaccharides are built together into a semi-crystalline structure known as a starch granule or grain.

The pattern of formation provides the morphological features which are used to identify starches (Fig. 5.1). The formation begins at a nucleus, called the hilum (pl. hila), and the sugar chains extend radially from this point. As starches grow, the carbohydrate chains can be deposited evenly in all directions, leading to a starch with a centric hilum, or they can be deposited preferentially on one side, leading to starches with an eccentric hilum. Throughout the starch there are alternating bands of higher and lower crystallinity. In some taxa, some of these layers of varying crystallinity are visible as darker and lighter bands, which are called lamellae. The level of hydration of the starch and the refractive index of the mounting medium can change the visibility of the lamellae. The alternating layers also result in one of the diagnostic features of the starch granules, that is, the appearance of a extinction or polarization cross when viewed under cross-polarized light. Finally, the manner of growth in the cell can determine both the overall shape of the starches as well as features of their surface. If there is one starch per amyloplast, the starches are called 'simple' starches, but if several starches grow in the same amyloplast, they are called compound starches. Often, there are several amyloplasts within a single plant cell, and the starches can press against each other as they grow. When the starches are all generally the same size this leads to polyhedral starches with flat pressure facets, such as in maize. If the starches are bimodal, as is the case with the Triticeae, this results in the larger starches having a golf ball-like pockmarked appearance, with surface dimples where the smaller starches pressed against them.

While much of the variation among taxa is under genetic control, it is important to note that starches, like phytoliths, are subject to problems of multiplicity and redundancy. Starch morphologies 
can considerably overlap among both closely and distantly related taxa [for example, the similarities among the Triticeae (Piperno et al. 2004), and between the Triticeae and Capsicum (Perry et al. 2007)]. There can be several starch morphologies present in each plant, both within a single organ [e.g., the bimodal starch types seen in the seeds of Triticeae (Stoddard 1999)], and between organs of the same plant (seeds and roots, or seeds and pollen). The shape of starches can change as the plant ages, as well (Evers 1971; MacGregor and Ballance 1980). Care must be taken when developing a reference collection to sample broadly across taxa, as well as deeply within a species, in order to capture the full range of potential morphologies (see for example Lentfer 2009).

\section{Starch as an archaeological marker}

While starch has a long history of study and use as a component of food, its application as an archaeological marker developed only in recent times. The consistent morphological differences of starch granules produced by certain taxa was studied in the late 19th century by a variety of continental scholars (e.g., Nägeli 1858). In 1913, an American medical doctor by the name of Edward Tyson Reichert published a large compendium of figures and descriptions of starches (Reichert 1913), most of which had been produced by his two "assistants", Dr. Elizabeth E. Clark and Dr. Martha Bunting. Reichert was interested in how biochemical markers including starches, proteins, and the like, might be used to uniquely identify species. In the two-volume, nearly 900-page treatise (which Reichert nevertheless referred to as a "report of a preliminary investigation") Reichert, Clark, and Bunting provided detailed morphological and biochemical descriptions of starches from a large number of taxa. Their systematic approach confirmed that many starch morphologies were unique to specific taxa, and their research laid the foundation for the use of starch as a marker in archaeology.

In the late 1920s, Johannes Grüss found starch granules, bacteria, and yeast cells in the residues on Egyptian amphora that had been used to store beer (Grüss 1929). This was one of the first studies to use starch analysis not only to identify food residues, but also the food processing steps involved: Grüss identified marks on the starches that indicated they had been sprouted, further clarifying the beer-making procedure. Despite this early progress, it wasn't until much later, after Donald Ugent reported starch granules in desiccated tubers from Peru (Ugent et al. 1982), that the potential for starch 
analysis to assist in the identification of ancient plant materials was more broadly adopted. The feasibility of the analysis of individual starches isolated from residues on stone tools was first explored by an honor's thesis at the University of Queensland in 1988 (Higgins 1988), and publications in highimpact journals quickly followed (Fullagar et al. 1996; Loy et al. 1992; Piperno and Holst 1998). Since that time, starch granules have been recovered from a variety of archaeological materials and used to document many aspects of human interaction with plants (Barton and Matthews 2006).

Because of its abundance in many of the foods targeted by humans, starch has the potential to be found in almost any context in which people processed, prepared, or consumed food items. Starch can therefore be recovered from plant processing tools such as grindstones and cooking utensils such as pottery. Starch from barley has been found on early (c. 3000 BC) funnels and beakers from the Mijiaya site in North China (J. Wang et al. 2016) as well as on vessels from several sites in middle Egypt that had been used to make or store beer from c. 2000-1200 BC (Samuel 1996a). Starch granules, in combination with phytoliths, micro-charcoal, and fungal remains, were found in charred cooking pot residues on pottery from the pampas in Argentina (Musaubach and Berón 2017), showing the consumption of both wild and domesticated plants. Furthermore, this study highlighted the importance of considering multiple kinds of microparticles and other residues (in this case, fatty acids analyzed by gas chromatography) - the more detailed analysis allowed the authors to confirm the use of maize (Zea mays) and to explore how it had been processed.

Starch is also preserved on tools. Analysis of flakes from Neanderthal sites in France confirmed their use of starchy plants (B. L. Hardy 2004; B. L. Hardy and Moncel 2011). Several grindstones from Gravettian contexts within sites in Italy, Russia and the Czech Republic also preserved starch from a variety of plants, including Typha spp. (Aranguren et al. 2007; Revedin et al. 2010). This evidence of flour-making suggested that advanced processing techniques of starchy plant material were common well before agriculture. Starches found on grindstones from the Last Glacial Maximum in China also indicated the use of a large number of taxa, suggesting an increased reliance on plant foods during this period of climatic challenges and general resource scarcity (Liu et al. 2013). Starches recovered from stone tools in highland Ecuador demonstrated the early dispersal and use of maize (Pagán-Jiménez et al. 2015). Stone flakes and grindstones are not the only tools where starch may be found - a recent 
study has also found starches from maize and other local foods on shell scrapers from the Bahamas (Ciofalo et al. 2018).

Starches have been recovered from sediments and used to reconstruct site-use patterns (Balme and Beck 2002), though there are many potential sources of bias with this approach (Haslam 2004; Hutschenreuther et al. 2017). The potential pathways by which starches could be preserved in sediments (such as adhesion to clay particles as proteins do, for example) are not yet understood, and further research on these are needed.

Dental calculus is increasingly used as a target for starch recovery, for several reasons. Calculus forms during the lifetime of the individual, and as it forms it traps food remains within a matrix which is composed of bacterial proteins and mineral crystals (predominantly calcium phosphate in several different mineral forms) (Jin and Yip 2002; Lieverse 1999). The calculus becomes increasingly mineralized during the individual's lifetime, and after the death of that individual it remains a relatively stable environment. This seems to provide a protected environment that contributes to the long-term preservation of starches. Furthermore, because calculus forms in the mouth, it is a direct record of the kinds of plants that have been directly introduced into the oral cavity. This will predominantly represent food items, but other activities can also be recorded, such as oral processing of plant-based building materials (e.g. basket making) or non-dietary plant use (medicinal / recreational)(Radini et al. 2017). Other microparticles such as charcoal, phytoliths, fungal spores, pollen, and mineral particles, may also be recovered from calculus, and may likewise represent both consumption and non-dietary behaviors (K. Hardy et al. 2016; Mackie et al. 2017; Radini et al. 2019). Starch granules have been recovered from calculus from Neanderthals (Fiorenza et al. 2015; K. Hardy et al. 2016; Henry et al. 2011, 2014; Power et al. 2018) and from early modern humans in Europe (Power, Salazar-García, Straus, et al. 2015; Power et al. 2016). Starch from calculus has also provided a wealth of information about trade networks, and the spread of people and agriculture across the Americas, including in Peru (Piperno and Dillehay 2008), Brazil (Boyadjian et al. 2016), and Mexico (King et al. 2017). Calculus is rarely examined for starches alone; instead researchers will combine methods, for example looking at starches and other micro-remains together (Cummings et al. 2018; e.g., Tromp and Dudgeon 2015), or combining starch analysis with other methods of dietary reconstruction, such as stable isotope analysis on collagen (T. T. Wang et al. 2016), MS-based analysis of residues in the calculus (Gismondi et al. 
2018), or analysis of calculus proteins and DNA (Warinner et al. 2014). In general, studies that combine analysis and identification of starches with other methods provide the most complete information about diet and behavior in the past.

One of the aspects of starch granules that makes them a useful and attractive tool for archaeologists interested in food behavior is that the physical appearance of starches changes as a result of processing. These changes, including things like swelling, cracking, and partial gelatinization (the irreversible breakdown of bonds among linked amylose and amylopectin chains, leading to the loss of crystallinity) appear as the result of different kinds of processing. For example, Babot (2003) demonstrated that air drying, roasting, charring, freezing, and milling all produced distinctive damage to plants native to Central and South America including potatoes, maize, and beans. Similar results were shown for North American food plants (Messner and Schindler 2010) and a variety of Old World domesticated species (Henry et al. 2009; J. Wang et al. 2017). Though modern samples may predictably be altered by processing, interpreting damage on archaeological materials remains challenging. In contexts where the likely processing steps are well-known, damage to starch has been a useful indicator of the exact steps used. For example, processing marks on the starches preserved in Egyptian pottery crusts showed that the brewers used malted grain and heated the wort at different temperatures depending on the brew (Samuel 1996b). Partially gelatinized starches recovered from dental calculus of Neanderthals suggests they consumed grains, including wild relatives of wheat and barley, that had been heated in the presence of water (Henry et al. 2011). However, many changes to starch morphology can occur for reasons other than food processing, including taphonomic effects and laboratory processing conditions (discussed below). A full understanding of these other processes is necessary before starch damage is used to interpret things like multistep processing.

\section{Methods to recover starch}

\section{From modern reference materials}

The first step in any analysis must be to create a reference collection of starches from modern plants. For any region it is best to sample not only the starchy parts of the plants of interest (e.g., the seeds from wheat or barley) but also any other potentially starch-containing plant organs (e.g., wheat pollen), as well as starchy parts of other native species (e.g. the seeds of 'weed' grasses such as goat 
grass). Starch granule size and morphology can vary slightly among plants of different ages and from different growing conditions, so it is important to include samples from multiple individual plants.

The sampling of starches from modern plants is relatively simple. The starchy part of the plant is cut to expose the interior. A scalpel is used to scrape a very small amount off the plant directly onto the slide. Large chunks are flattened with the side of the scalpel or removed. A 10-12\% solution of glycerin in distilled water is added (higher glycerin concentrations may obscure important features of the starches) and a cover glass is put over the sample. It may be necessary to gently press down on the cover glass to further disperse the starches. The samples are then examined at 200-400x magnification under a transmitted light microscope which has two polarization filters that are capable of crosspolarizing. A microscope with an x-y stage is preferred but it is possible to use a circular stage.

The starches should be examined, photographed at multiple different focal planes, and described. There is no peer-reviewed published terminology, but many in the field contributed to the International Code for Starch Nomenclature in 2011, which is available online (ICSN 2011). In general a description should record if the starch forms singularly or in compounds, the overall shape in both two and three dimensions, the position and visibility of the hilum, the appearance of the lamellae, the presence and appearance of fissures, the texture of the surface, the appearance of the polarization cross, and whether the collection of starches from a single plant part has one starch type (isomorphic) or several distinct types (heteromorphic). Most plants will show some variation with their starches, so it is important to document the degree and frequency of this variation (e.g., using terms like most, some, rare, etc.). Ideally, these would be supported by actual frequency counts, but this is not possible in many cases, and not always useful in distinguishing starch types.

\section{From dental calculus}

The methods to recover starch granules from dental calculus have varied. Most protocols begin with removing the calculus from the tooth using a dental pick or scalpel, and chemically or physically breaking apart the calculus if necessary, and then examining using light microscopy or scanning electron microscopy (SEM). In cases where the calculus deposit is small, and the tooth is separated from the bone, then some practitioners recommend a kind of 'wash', using dilute $\mathrm{HCl}$ or water and sonicating the entire tooth (Boyadjian et al. 2007). While this method often results in the recovery of a large number of starches, it may be problematic in that it is more difficult to control or test for 
contamination, and when $\mathrm{HCl}$ is used, this process can damage the enamel surface of the tooth. Other kinds of pre-sampling contamination removal include brushing with a soft, single-use toothbrush.

If the calculus deposit is large enough, it should be removed in a large, single chunk. A dental scaler or scalpel is used to pull the calculus off the tooth, usually onto a prepared sampling surface, such as a piece of autoclaved laboratory aluminum foil, a folded piece of weighing paper, or directly into a microcentrifuge tube. After collection, some researchers further decontaminate the calculus using, for example, multiple washes in distilled water (Tavarone et al. 2018), or weak sodium hydroxide (Soto et al. 2019). However, such methods are still problematic in that it is unclear if contaminating starches are fully removed in the former case, and whether the method would work on real dental calculus in the latter case. Further testing to refine decontamination methods is needed. After cleaning, the majority of the calculus chunk can be chemically or physically broken down. Physical disaggregation by grinding in a mortar (preferably made from agate) can reduce the particle size but may damage starches and may leave starch and other microparticles trapped in the calculus matrix. Mechanical disaggregation using sonication has proven useful for releasing trapped particles from the calculus (Radini et al. 2019). Chemical processing can be more effective at releasing the starches but may also damage them if too strong solutions are used for too long. Some researchers have used dilute ( 2\%) $\mathrm{HCl}$ to break up the calculus, but a recent paper has demonstrated that EDTA provides better results and does not damage the starch (Tromp et al. 2017). The broken-down calculus is then mounted and examined under transmitted light microscopy, usually at 400x magnification. Many mount the calculus in a glycerin solution (10-12\%), but some mount directly in EDTA or $\mathrm{HCl}$ in order to observe the dissolution of the calculus to help determine that the starches are directly released from the calculus.

\section{From pottery}

Pottery vessels were often used as food storage and processing implements, and therefore can contain a large amount of starch. Sometimes starches are preserved in the charred food crusts remaining inside cooking vessels. This crust is removed with a scalpel or other blade. Some researchers then dissolve the crusts in $10 \% \mathrm{H}_{2} \mathrm{O}_{2}$ to free the starches (e.g., Saul et al. 2012); others will use density separation by heavy liquid flotation to separate the starches from other material (e.g., J. Wang et al. 2016), some do both (e.g., García-Granero et al. 2017). Heavy liquid separation relies on the general principle that starches have a specific gravity of around $1.2 \mathrm{~g} / \mathrm{cm} 3$, and will therefore float when in a 
solution that has a specific gravity of $1.3 \mathrm{~g} / \mathrm{cm} 3$. Sodium polytungstate (SPT) is the most often used heavy liquid, but it should be noted that SPT can damage starches if they are left in solution for too long. The density separation process therefore requires a centrifuge to pull down the denser material through the SPT, leaving the starches floating on top. The resulting SPT / starch mixture is transferred to a new tube and diluted with enough water to lower the specific gravity below 1.2, and centrifuged again to concentrate the starches.

Starches may also be preserved on the surfaces of the pottery in the absence of food crusts. In such cases, it may be possible to wash a small area with distilled water and a sterile brush, and to collect and analyze the resulting liquid suspension (Duke et al. 2018). Finally, smaller sherds can be sonicated in beakers with a small amount of water to extract starches. The starches are then separated from the remaining suspension in the beaker using heavy liquid flotation. It is especially important to collect contamination control samples (see below) when using either of the latter water wash methods, as the sampled surfaces often have no protection from the surrounding environment.

\section{From stone tools}

Stone tools have also been targeted as potential sources of ancient starches. Some analysts have directly examined the surface of the tools under a dissecting microscope with cross polarized light (e.g., B. L. Hardy 2004). This method allows a better understanding of the distribution of residues across the surface of the tool but often does not have high enough magnification to identify the botanical origin of the starches. Instead, the residues must be removed from the tool and examined using transmitted light microscopy. Flaked stone tools are often sonicated, as with pottery sherds, and the resulting liquid centrifuged or evaporated to concentrate the residues. A spot sampling method may also be employed, in which a small amount of water is placed in a spot of known area (e.g., a circle with a $1 \mathrm{~cm}$ diameter). The water is agitated with a pipette and then collected. The washing of that spot is repeated several times and all the water collected together. This method may not extract all of the starches but can provide some information about the variable distribution of starches across the tool, when multiple spot-samples from the same tool are compared. For grindstone tools, a multi-step processing method can help to provide a means of contamination control. The grindstone can first be dry brushed, then wet brushed, then 'picked' (a probe is inserted into visible pits in the tool surface to pull out embedded material), and finally sonicated (as described in Piperno 2006). If the tool is too large to be sonicated entire, then an electric ultrasonic toothbrush can also be used (Liu et al. 2018). The material removed at 
each sampling step is individually examined, with the dry and wet brushing samples representing more likely contaminated samples and the picking and sonication samples more likely to contain a majority of endemic starches.

\section{From bone}

Bone can also be sampled for starches using the spot sampling method as described for stone tools. This is a useful method for testing for contamination. Bones are less likely to have been part of the plant food processing procedures, but are often handled in the same laboratory settings as tools and teeth, and therefore can provide a record of post-excavation contamination.

\section{From sediments}

Sediments have been examined for starches, and some have used this method to explore differences in site activity areas (Balme and Beck 2002). Usually the sediment samples are minimally processed, and heavy liquid flotation is used to separate the starch from the heavier sediment particles. However, there are concerns about how small changes in sediment properties might affect the long term survival of these starches (Haslam 2004; Hutschenreuther et al. 2017), so more research is needed before starches in unprotected environments in sediments are regularly used.

\section{Identifying starch granules}

The most common methods for identifying starches rely on the comparison of the starch morphology to a reference collection. This is usually done by 'expert analysis,' though recently some have attempted computer image processing methods that allow post-hoc assignment of the starches to certain types or species (Coster and Field 2015; Liu et al. 2014; Wilson et al. 2010). While there is great potential with these kinds of computerized methods, they are limited in that most computer-based image processing programs can only 'see' the starch in two dimensions, while the three-dimensional information is lost. This means that automated algorithms have less success identifying taxa in which the starches have very different outlines in plane view and in side view. 
The features which can reliably differentiate starches are formation type, shape, appearance and position of the hilum, appearance of the extinction cross, appearance of the lamellae and surface features. If possible to see clearly, the formation type of the starch should be described as either simple or compound. If compound, the shape of the overall compound starch and the individual component granules should be described, as well as the frequency with which the compound breaks into components (i.e., how often the component granules are seen alone). Both the two-dimensional and three-dimensional shape of the starch should be described. Two-dimensional terms should be used especially when the shape varies among the axes of the granule. For example, a starch my be circular in plane view, but compressed or flattened in side view, and lenticular in 3-d. Usually if a 2-d shape is encompassed within a 3-d shape it is not necessary to use both - a spherical starch will always be circular in 2-d, and a polyhedral starch will be polygonal in 2-d. The hilum is usually described as centric or eccentric and visible or invisible. A visible hilum can be a single refractive point, or marked by one or more small fissures, or an open vacuole. The extinction cross always centers on the hilum, and can therefore also be centric or eccentric. The general orientations of the arms of the cross are determined by the orientation of the two polarization filters on the microscope, but the arms can be thick or thin, straight or bent, invisible at the center, or widening towards the margins of the starch. The lamellae can be visible or invisible. If visible, they can vary in thickness, density, and completeness around the starch. Fissures can appear at the hilum, as single lines, T-shaped, Y-shaped, X-shaped or stellate cracks. Some fissures appear at the margins of granules rather than at the hilum. When describing fissures, care should be taken to differentiate those that are naturally forming in the starch and therefore potentially diagnostic from those that are caused by damage. The surface of the starch may be marked by pressure facets of various kinds, or may be smooth or textured. Finally, some taxa have distinctive features which do not fall into the previous categories. Some Triticeae have an equatorial groove, which is a thin crease that runs around the circumference of the mostly lenticular starches (Fig 5.1k). In many Fabaceae, there is a very large, ragged fissure that divides the granule along the long axis - this is known as the longitudinal cleft fissure or LCF (Fig. $5.1 \mathrm{m \& n}$ ). Some of the Iridaceae have two distinct lines or creases that run from the hilum to the distal marginal corners of the hemispherical or sub-triangular component granules (Fig. 5.1 o\&p). All of the terms used above, as well as several other useful terms are defined by the ICSN 2011. Size is sometimes used to differentiate starches, but care must be taken here, since the size of many species overlap considerably, and the size of starches can change as the plant ages. As mentioned above, creating a reference collection of 
sufficient depth and breadth is necessary for confident identification. It is always recommended for the researcher to indicate their degree of confidence in their identification. It is more accurate to state that an archaeological starch has morphology that is consistent with that of a modern reference starch, than to say that an archaeological starch is from a particular plant.

There are several objects that are of a similar size to, and that share some features with starches. These objects can occur in a variety of archaeological contexts and can confuse starch researchers. First, coccoliths can often occur in archaeological samples (see Chapter 2 by Young, this volume), and their flat appearance is not always immediately visible (starches are almost always thicker and less plate-like than coccoliths, but it can be difficult to turn coccoliths to see their complete shape). Coccoliths also often have a central point that looks like a hilum, and a polarization cross. However, unlike in starches, this polarization cross will always appear twisted (Fig. $5.2 \mathrm{a} \& \mathrm{~b}$ ). Small bubbles of oil or air occasionally have a birefringence pattern at the very margin of the bubble, but these bubbles lack internal features that identify starches and the cross never appears at the center (Fig. 5.2 c\&d). Fibers or cell walls from soft woods often have bordered pits, which can sometimes appear as a row of donut-like shapes. When viewed under cross-polarized light they have an extinction cross. However, starches do not form attached to a fiber, and the central hole of the bordered pit is usually much larger than the hilum of a starch. Furthermore, the fiber itself if flat, and the margin of the bordered pit is usually diffuse (Fig. 5.2 e\&f). Note that while bordered pits come from wood, they are very common in modern paper products and therefore unreliable markers of past use of wood. Undecorated chrysophycean stomatocysts (see Chapter 3 by Stone and Yost in this volume) have a solid outer shell that sometimes cross polarizes (Fig. 5.2 g\&h). They are distinguished from starches in that they never have a cross in the center (in fact, they have a hollow center) and they often have a single pore in the outer wall. Finally, spherulites of other non-starch polymers can be observed on slides (Fig. 5.2 i-l). These objects often have quite distinctive concentric rings when viewed under cross-polarized light, and show some degree of refractive quality when viewed under single-polarized light (note the darker areas in the 'brightfield' images of these objects). They often appear in pairs or groups (as in Fig. 5.2 kl), and often disappear from a slide after some time. While it is currently unclear what these objects are, they are not starch. 


\section{Potential problems in starch research}

\section{Contamination modern and ancient}

Contamination of ancient material by modern starch is the largest challenge facing starch research today. Starch granules are ubiquitous in modern environments. They are present in our foods, used in a large number of industrial processes, and added to a variety of products including paper, soaps, and adhesives. There are no reliable visual markers that can differentiate modern and ancient starches, so once modern starch has been introduced to a sample it is impossible to tell which starches are endemic, and which are contamination. Some of the species most interesting for archaeologists are also the most commonly found as contaminants, including wheat, potato, and maize (Fig. 5.3). Starch researchers must therefore use protocols that minimize the risk of contamination, test sampling and work spaces for contamination, take abundant control samples, and, importantly, publish the results of these sampling and control tests in full detail to ensure that others can fully trust their results.

Field, laboratory and museum settings often have contaminating starches (Crowther et al. 2014), and the collection of samples should be done in a manner to minimize contamination. While it may not be possible in all situations, a strict sampling protocol that makes use of full-body covering and a positive-pressure tent may help ensure that environmental and personal starches cannot contaminate artifacts during excavation (Mercader et al. 2017). Autoclaved tools should be used whenever possible, and cleaned with a 5\% sodium hydroxide solution and rinsed where not (Gismondi et al. 2018). Laboratory supplies such as soap, paper towels, gloves, foil, and plastic ware should be tested prior to use. Liquids can be mounted directly onto slides and examined. Solids can be spotwashed (as described for stone tools, above) or, if small enough, washed directly. The material is placed in a $50 \mathrm{ml}$ tube with c $30 \mathrm{ml}$ of distilled water. The tube is vigorously shaken, and the material removed using autoclaved forceps. The tube is centrifuged and the supernatant removed, and the remaining pellet mounted and examined. The areas for the preparation of modern samples and reference material should be physically separated from those where ancient material is handled, preferably in separate rooms. The preparation and analysis areas should be cleaned regularly (once a week if possible) with water and a 5\% sodium hydroxide solution (Crowther et al. 2014). Additionally, once a month the containers of mounting media (water and glycerin) should be tested, emptied and replaced.

While the cleaning is important, it may not be sufficient to remove all of the potential contaminants. A “wipe test” performed before and after the weekly cleaning can help assess the background contamination level. A wipe test involves spraying a small amount of distilled water onto 
an area of known size (for example, by using a cleaned plastic frame that outlines a 20x20cm square) on the main sample processing areas. A kimwipe held by autoclaved foreceps is then used to carefully and deeply wipe the surface. The kimwipe is then transferred to a $50 \mathrm{ml}$ tube containing roughly $20 \mathrm{ml}$ of distilled water and allowed to rest for 1 minute. After this, the forceps are used to first swish the kimwipe around in the water and then squeeze the wipe against the walls of the tube to remove as much water as possible. The tube is centrifuged 3krpm for 7 minutes, and most of the supernatant removed with a pipette, leaving roughly 50-100ul in the tube. The remaining volume is estimated by sucking it up into a pipette set to 150ul, and reducing the volume setting of the pipette until the liquid is just at the very end of the tip and no air remains. Finally, the entire volume is mixed with a pipette, and 10ul of the liquid is mounted and examined. Knowing the volume remaining allows the calculation of the total number of contaminants found in the $20 \times 20 \mathrm{~cm}$ square. Publications of archaeological material should also include the results of the wipe tests that occurred in the same periods in which the archaeological material was examined.

For each investigation of archaeological materials, it is important to collect control samples from the site, from the museum (when applicable) and from the laboratory. Site control samples include things like unmodified animal bones, surrounding sediments, human cortical bone surfaces (when collecting calculus, for example, I like to do a water wash of the surface of the ascending ramus of the mandible). These materials can record both ancient and modern contamination sources, since they will be exposed to similar burial settings, and often handled by excavators, archaeologists, and curators in a manner similar to the target samples.

Many researchers in the field are working towards better methods for establishing authenticity criteria for ancient starches, including exploring the potential for molecularly identifying starches, and understanding the taphonomic pathways by which starches may be preserved (Mercader et al. 2018) . This remains an area of active research.

\section{Other issues}

While starch granules can be strong markers of the presence of certain plants within the diets of individuals or populations, there are limits to kinds of questions that starch granules can be used to answer. Starch granules are not present in all plants, and the relative abundance of starches in an archaeological sample does not directly reflect the frequency of consumption of that plant, even when 
controlling for variable rates of starch production within the plant (Leonard et al. 2015; Power, SalazarGarcía, Wittig, et al. 2015). Therefore, starches should not be used to discuss the exact number of plants in the diet, nor can they be used to discuss to relative importance of particular species. Questions of diet breadth (i.e., the number of different plants consumed) can be explored, but only when considering a large enough number of samples from a single population (Leonard et al. 2015). Finally, because starch granules can be easily removed from the archaeological record, the absence of a particular type of starch does not necessarily indicate that the plant was not consumed. Researchers must take care that their research question is one that can be answered by these microremains.

There are currently several published and online databases of starch granules, but all such databases are organized by taxon rather than by shape, in part because of the difficulty of agreeing on terms for shapes, and in part because starches from single plants often have variable morphologies. This is an area where the starch community could improve, potentially by using data-sharing platforms such as FigShare.

Furthermore, starch research in archaeology is still developing and there remain methodological concerns to resolve. For example, the use of heavy liquid flotation can be extremely valuable, especially for 'dirty' samples that contain many non-starch particles, such as pottery crusts and sediment samples. However, recent work from the author's laboratory has demonstrated that heavy liquid flotation can heavily bias the recovered starch assemblages, especially against partially gelatinized and damaged starch granules (Henry et al. 2016). The starch sample processing method therefore needs to be tailored to the research question and the sample type. If food processing is of interest to the researcher, then heavy liquid flotation should be avoided. Also, methods to test for and minimize the impact of contamination are not equally applied, and several authors have raised concerns with the authenticity of ancient starches. Further testing for contamination and publication of these contamination tests are needed for ancient starch research to become more solidly established.

\section{Conclusion}

While the potential problems described in this last section deserve serious consideration, if they are properly addressed, starch research can be a powerful tool for exploring questions about human food preferences and processing. 


\section{References Cited}

Aranguren, B., Becattini, R., Lippi, M. M., \& Revedin, A. (2007). Grinding flour in Upper Palaeolithic Europe (25 000 years bp). Antiquity, 81, 845-855.

Babot, M. del P. (2003). Starch grain damage as an indicator of food processing. In D. M. Hart \& L. A. Wallis (Eds.), (pp. 69-81). Pandanus Press.

Balme, J., \& Beck, W. E. (2002). Starch and charcoal: Useful measures of activity areas in archaeological rockshelters. Journal of Archaeological Science, 29, 157-166.

Barton, H., \& Matthews, P. J. (2006). Taphonomy. In R. Torrence \& H. Barton (Eds.), Ancient Starch Research (pp. 75-94). Walnut Creek, California: Left Coast Press.

BeMiller, J. N., \& Whistler, R. L. (2009). Starch: chemistry and technology. Academic Press.

Boyadjian, C. H. C., Eggers, S., \& Reinhard, K. (2007). Dental wash: a problematic method for extracting microfossils from teeth. J. Arch. Sci., 34, 1622-1628.

Boyadjian, C. H. C., Eggers, S., \& Scheel-Ybert, R. (2016). Evidence of plant foods obtained from the dental calculus of individuals from a Brazilian shell mound. In Wild Harvest: Plants in the Hominine and Pre-agrarian Human Worlds (pp. 215-240). Oxbow Books Oxford.

Ciofalo, A. J., Keegan, W. F., Pateman, M. P., Pagán-Jiménez, J. R., \& Hofman, C. L. (2018). Determining precolonial botanical foodways: starch recovery and analysis, Long Island, The Bahamas. Journal of Archaeological Science: Reports, 21, 305-317. doi:10.1016/j.jasrep.2018.07.022

Coster, A. C. F., \& Field, J. H. (2015). What starch grain is that? - A geometric morphometric approach to determining plant species origin. Journal of Archaeological Science, 58, 9-25. doi:10.1016/j.jas.2015.03.014

Crowther, A., Haslam, M., Oakden, N., Walde, D., \& Mercader, J. (2014). Documenting Contamination in Ancient Starch Laboratories. Journal of Archaeological Science. doi:10.1016/j.jas.2014.04.023 
Cummings, L. S., Yost, C., \& Sołtysiak, A. (2018). Plant microfossils in human dental calculus from Nemrik 9, a Pre-Pottery Neolithic site in Northern Iraq. Archaeological and Anthropological Sciences, 10(4), 883-891. doi:10.1007/s12520-016-0411-3

Duke, G. S., Vásquez-Sanchez, V. F., \& Rosales-Tham, T. E. (2018). Starch grain evidence of potato consumption at the Late Moche (AD 600-850) site of Wasi Huachuma, Peru. Journal of Archaeological Science, 100, 74-79. doi:10.1016/j.jas.2018.10.006

Evers, A. D. (1971). Scanning Electron Microscopy of Wheat Starch. III. Granule Development in the Endosperm. Starch - Stärke, 23(5), 157-162. doi:10.1002/star.19710230502

Fiorenza, L., Benazzi, S., Henry, A. G., Salazar-García, D. C., Blasco, R., Picin, A., et al. (2015). To meat or not to meat? New perspectives on Neanderthal ecology. American Journal of Physical Anthropology, 156, 43-71. doi:10.1002/ajpa.22659

Fullagar, R., Furby, J., \& Hardy, B. L. (1996). Residues on stone artefacts: state of a scientific art. Antiquity, 70, 740-745.

García-Granero, J. J., Urem-Kotsou, D., Bogaard, A., \& Kotsos, S. (2017). Cooking plant foods in the northern Aegean: Microbotanical evidence from Neolithic Stavroupoli (Thessaloniki, Greece). Quaternary International. doi:10.1016/j.quaint.2017.04.007

Gismondi, A., D’Agostino, A., Canuti, L., Di Marco, G., Martínez-Labarga, C., Angle, M., et al. (2018). Dental calculus reveals diet habits and medicinal plant use in the Early Medieval Italian population of Colonna. Journal of Archaeological Science: Reports, 20, 556-564. doi:10.1016/j.jasrep.2018.05.023

Grüss, J. (1929). Saccharomyces winlocki, die Hefe aus den Pharaonengräbern. Tageszeitung für Brauerei, 27(59), 275-278.

Hardy, B. L. (2004). Neanderthal behavior and stone tool function at the Middle Palaeolithic site of La Quina, France. Antiquity, 78(301), 547-565.

Hardy, B. L., \& Moncel, M.-H. (2011). Neanderthal use of fish, mammals, birds, starchy plants and wood 125-250,000 Years Ago. PloS one, 6(8), e23768. 
Hardy, K., Radini, A., Buckley, S., Sarig, R., Copeland, L., Gopher, A., \& Barkai, R. (2016). Dental calculus reveals potential respiratory irritants and ingestion of essential plant-based nutrients at Lower Palaeolithic Qesem Cave Israel. Quaternary International, 398, 129-135. doi:10.1016/j.quaint.2015.04.033

Haslam, M. (2004). The decomposition of starch grains in soils: implications for archaeological residue analysis. J. Arch. Sci., 31, 1715-1734.

Henry, A. G., Brooks, A. S., \& Piperno, D. R. (2011). Microfossils in calculus demonstrate consumption of plants and cooked foods in Neanderthal diets (Shanidar III, Iraq; Spy I and II, Belgium). Proceedings of the National Academy of Sciences USA, 108(2), 486-491.

Henry, A. G., Brooks, A. S., \& Piperno, D. R. (2014). Plant foods and the dietary ecology of Neanderthals and early modern humans. Journal of Human Evolution, 69, 44-54. doi:10.1016/j.jhevol.2013.12.014

Henry, A. G., Debono Spiteri, C., Büdel, T., Hutschenreuther, A., Schmidt, S., \& Watzke, J. (2016). Methods to isolate and quantify damaged and gelatinized starch grains. Journal of Archaeological Science: Reports, 10, 142-146. doi:10.1016/j.jasrep.2016.09.003

Henry, A. G., Hudson, H. F., \& Piperno, D. R. (2009). Changes in starch grain morphologies from cooking. Journal of Archaeological Science, 36(3), 915-922.

Higgins, S. (1988). Starch grain differentiation on archaeological residues : a feasibility study (Honor’s Thesis). University of Queensland, Brisbane, Australia.

Hutschenreuther, A., Watzke, J., Schmidt, S., Büdel, T., \& Henry, A. G. (2017). Archaeological implications of the digestion of starches by soil bacteria: Interaction among starches leads to differential preservation. Journal of Archaeological Science: Reports, 15, 95-108. doi:10.1016/j.jasrep.2017.07.006

ICSN. (2011). The International Code for Starch Nomenclature. http://fossilfarm.org/ICSN/Code.html. Accessed 2 November 2011

Jin, Y., \& Yip, H.-K. (2002). Supragingival calculus: Formation and control. Critical Reviews in Oral Biology and Medicine, 13(5), 426-441. 
King, D. J., Searcy, M. T., Yost, C. L., \& Waller, K. (2017). Corn, Beer, and Marine Resources at Casas Grandes, Mexico: An Analysis of Prehistoric Diets Using Microfossils Recovered from Dental Calculus. Journal of Archaeological Science: Reports, 16, 365-379.

doi:10.1016/j.jasrep.2017.10.013

Lentfer, C. J. (2009). Building a comparative starch reference collection for Indonesia and its application to palaeoenvironmental and archaeological research. In Archaeological science under a microscope: Studies in residue and ancient DNA analysis in honour of Thomas H. Loy (pp. 80-101). Canberra: ANU E Press.

Leonard, C., Vashro, L., O’Connell, J. F., \& Henry, A. G. (2015). Plant microremains in dental calculus as a record of plant consumption: A test with Twe forager-horticulturalists. Journal of Archaeological Science: Reports, 2, 449-457. doi:10.1016/j.jasrep.2015.03.009

Lieverse, A. R. (1999). Diet and the aetiology of dental calculus. International Journal of Osteoarchaeology, 9, 219-232.

Liu, L., Bestel, S., Shi, J., Song, Y., \& Chen, X. (2013). Paleolithic human exploitation of plant foods during the last glacial maximum in North China. Proceedings of the National Academy of Sciences, 110(14), 5380-5385. doi:10.1073/pnas.1217864110

Liu, L., Ma, S., \& Cui, J. (2014). Identification of starch granules using a two-step identification method. Journal of Archaeological Science, 52, 421-427. doi:10.1016/j.jas.2014.09.008

Liu, L., Wang, J., Rosenberg, D., Zhao, H., Lengyel, G., \& Nadel, D. (2018). Fermented beverage and food storage in 13,000 y-old stone mortars at Raqefet Cave, Israel: Investigating Natufian ritual feasting. Journal of Archaeological Science: Reports, 21, 783-793. doi:10.1016/j.jasrep.2018.08.008

Loy, T. H., Spriggs, M., \& Wickler, S. (1992). Direct evidence for human use of plants 28,000 years ago: starch residues on stone artefacts from the northern Solomon Islands. Antiquity, 66, 898912.

MacGregor, A., \& Ballance, D. (1980). Hydrolysis of large and small starch granules from normal and waxy barley cultivars by alpha-amylases from barley malt. Cereal Chemistry, 57(6), 397-402. 
Mackie, M., Radini, A., \& Speller, C. F. (2017). The Sustainability of Dental Calculus for Archaeological Research. In Shallow Pasts, Endless Horiozons: Sustainability \& Archaeology:Proceedings of the 18th Annual Chacmool Archaeology Conference (pp. 74-81). http://eprints.whiterose.ac.uk/112715/. Accessed 25 September 2018

Mercader, J., Abtosway, M., Baquedano, E., Bird, R. W., Díez-Martín, F., Domínguez-Rodrigo, M., et al. (2017). Starch contamination landscapes in field archaeology: Olduvai Gorge, Tanzania. Boreas, 46(4), 918-934. doi:10.1111/bor.12241

Mercader, J., Akeju, T., Brown, M., Bundala, M., Collins, M. J., Copeland, L., et al. (2018). Exaggerated expectations in ancient starch research and the need for new taphonomic and authenticity criteria. Facets, 3(1), 777-798.

Messner, T. C., \& Schindler, B. (2010). Plant processing strategies and their affect upon starch grain survival when rendering Peltandra virginica (L.) Kunth, Araceae edible. Journal of Archaeological Science, 37(2), 328-336.

Musaubach, M. G., \& Berón, M. A. (2017). Food residues as indicators of processed plants in huntergatherers’ pottery from La Pampa (Argentina). Vegetation History and Archaeobotany, 26(1), 111-123. doi:10.1007/s00334-016-0581-z

Nägeli, C. (1858). Die Stärkekörner. Morphologishe, physiologishe, chemisch-physicalisch und systematisch-botansiche. Zurich: Verlag F. Schulthess.

Pagán-Jiménez, J. R., Rodríguez-Ramos, R., Reid, B. A., van den Bel, M., \& Hofman, C. L. (2015). Early dispersals of maize and other food plants into the Southern Caribbean and Northeastern South America. Quaternary Science Reviews, 123, 231-246. doi:10.1016/j.quascirev.2015.07.005

Perry, L., Dickau, R., Zarrillo, S., Holst, I., Pearsall, D. M., Piperno, D. R., et al. (2007). Starch fossils and the domestication and dispersal of chili peppers (Capsicum spp. L.) in the Americas. Science, 315, 986-988.

Piperno, D. R. (2006). Phytoliths: A comprehensive guide for archaeologists and paleoecologists. Lanham, Maryland: AltaMira Press. 
Piperno, D. R., \& Dillehay, T. D. (2008). Starch grains on human teeth reveal early broad crop diet in Northern Peru. Proceedings of the National Academy of Sciences, 105(50), 19622-19627.

Piperno, D. R., \& Holst, I. (1998). The presence of starch grains on prehistoric stone tools from the humid Neotropics: Indications of early tuber use and agriculture in Panama. J. Arch. Sci., 25, 765-776.

Piperno, D. R., Weiss, E., Holst, I., \& Nadel, D. (2004). Processing of wild cereal grains in the Upper Paleolithic revealed by starch grain analysis. Nature, 430, 670-673.

Power, R. C., Salazar-García, D. C., \& Henry, A. G. (2016). Dental calculus evidence of Gravettian diet and behaviour at Dolní Věstonice and Pavlov. In Dolní Věstonice II: Chronostratigraphy, Paleoethnology, Paleoanthropology (pp. 345-352). Academy of Sciences of the Czech Republic, Institute of Archaeology at Brno.

Power, R. C., Salazar-García, D. C., Rubini, M., Darlas, A., Harvati, K., Walker, M., et al. (2018). Dental calculus indicates widespread plant use within the stable Neanderthal dietary niche. Journal of Human Evolution, 119, 27-41. doi:10.1016/j.jhevol.2018.02.009

Power, R. C., Salazar-García, D. C., Straus, L. G., González Morales, M. R., \& Henry, A. G. (2015). Microremains from El Mirón Cave human dental calculus suggest a mixed plant-animal subsistence economy during the Magdalenian in Northern Iberia. Journal of Archaeological Science, 60, 39-46. doi:10.1016/j.jas.2015.04.003

Power, R. C., Salazar-García, D. C., Wittig, R. M., Freiberg, M., \& Henry, A. G. (2015). Dental calculus evidence of Taï Forest Chimpanzee plant consumption and life history transitions. Scientific Reports, 5, 15161. doi:10.1038/srep15161

Radini, A., Nikita, E., Buckley, S., Copeland, L., \& Hardy, K. (2017). Beyond food: The multiple pathways for inclusion of materials into ancient dental calculus. American Journal of Physical Anthropology, 162(S63), 71-83. doi:10.1002/ajpa.23147

Radini, A., Tromp, M., Beach, A., Tong, E., Speller, C., McCormick, M., et al. (2019). Medieval women’s early involvement in manuscript production suggested by lapis lazuli identification in dental calculus. Science Advances, 5(1), eaau7126. doi:10.1126/sciadv.aau7126 
Reichert, E. T. (1913). The differentiation and specificity of starches in relation to genera, species, etc. Washington, DC.: The Carnegie Institution of Washington.

Revedin, A., Aranguren, B., Becattini, R., Longo, L., Marconi, E., Lippi, M. M., et al. (2010). Thirty thousand-year-old evidence of plant food processing. Proceedings of the National Academy of Sciences, USA, 107, 18815-18819.

Samuel, D. (1996a). Investigation of ancient Egyptian baking and brewing methods by correlative microscopy. Science, 273, 488-490.

Samuel, D. (1996b). Archaeology of ancient Egyptian beer. Journal of the American Society of Brewing Chemists, 54(1), 3-12.

Saul, H., Wilson, J., Heron, C. P., Glykou, A., Hartz, S., \& Craig, O. E. (2012). A systematic approach to the recovery and identification of starches from carbonised deposits on ceramic vessels. Journal of Archaeological Science, 39(12), 3483-3492. doi:10.1016/j.jas.2012.05.033

Sivak, M. M., \& Preiss, J. (1998). Starch: Basic science to biotechnology. (S. L. Taylor, Ed.) (Volume 41.).

Soto, M., Inwood, J., Clarke, S., Crowther, A., Covelli, D., Favreau, J., et al. (2019). Structural characterization and decontamination of dental calculus for ancient starch research. Archaeological and Anthropological Sciences. doi:10.1007/s12520-019-00830-7

Stoddard, F. L. (1999). Survey of Starch Particle-Size Distribution in Wheat and Related Species. Cereal Chemistry, 76(1), 145-149. doi:10.1094/CCHEM.1999.76.1.145

Tavarone, A., Colobig, M. de los M., Passeggi, E., \& Fabra, M. (2018). Cleaning protocol of archaeological dental calculus: A methodological proposal for vegetable microremains analysis. American Journal of Physical Anthropology, 167(2), 416-422. doi:10.1002/ajpa.23630

Tromp, M., Buckley, H., Geber, J., \& Matisoo-Smith, E. (2017). EDTA decalcification of dental calculus as an alternate means of microparticle extraction from archaeological samples. Journal of Archaeological Science: Reports, 14, 461-466. doi:10.1016/j.jasrep.2017.06.035 
Tromp, M., \& Dudgeon, J. V. (2015). Differentiating dietary and non-dietary microfossils extracted from human dental calculus: the importance of sweet potato to ancient diet on Rapa Nui. Journal of Archaeological Science, 54, 54-63. doi:10.1016/j.jas.2014.11.024

Ugent, D., Pozorski, S., \& Pozorski, T. (1982). Archaeological potato tuber remains from the Casma Valley of Peru. Economic Botany, 36(2), 182-192.

Wang, J., Liu, L., Ball, T., Yu, L., Li, Y., \& Xing, F. (2016). Revealing a 5,000-y-old beer recipe in China. Proceedings of the National Academy of Sciences, 113(23), 6444-6448. doi:10.1073/pnas.1601465113

Wang, J., Liu, L., Georgescu, A., Le, V. V., Ota, M. H., Tang, S., \& Vanderbilt, M. (2017). Identifying ancient beer brewing through starch analysis: A methodology. Journal of Archaeological Science: Reports, 15, 150-160. doi:10.1016/j.jasrep.2017.07.016

Wang, T. T., Fuller, B. T., Wei, D., Chang, X. E., \& Hu, Y. W. (2016). Investigating Dietary Patterns with Stable Isotope Ratios of Collagen and Starch Grain Analysis of Dental Calculus at the Iron Age Cemetery Site of Heigouliang, Xinjiang, China. International Journal of Osteoarchaeology, 26(4), 693-704. doi:10.1002/oa.2467

Warinner, C., Rodrigues, J. F. M., Vyas, R., Trachsel, C., Shved, N., Grossmann, J., et al. (2014). Pathogens and host immunity in the ancient human oral cavity. Nature Genetics, 46(4), 336344. doi:10.1038/ng.2906

Wilson, J., Hardy, K., Allen, R., Copeland, L., Wrangham, R., \& Collins, M. (2010). Automated classification of starch granules using supervised pattern recognition of morphological properties. Journal of Archaeological Science, 37(3), 594-604. doi:10.1016/j.jas.2009.10.024 


\section{Figures}

Figure 5.1: Starches from modern plants demonstrating their variation

All boxes $50 \mu \mathrm{m}$ each side. a\&b Atriplex haliumus seed starches (many of the starches in the Chenopodiaceae family are very small compound granules that fracture into tiny component granules); c\&d Malva sylvestris root starch; e\&f Nuphar lutea rhizome starch, with distinctive small linear to stellate fissures at the hilum; g\&h Trapa natans seed starch, with one simple starch with eccentric hilum and one compound starch, both with very visible lamellae near the hilum; i\&j Triticum aestivum seed starch showing the bimodal size distribution and surface dimples on the large granule. k\&l Triticum aestivum seed starch viewed from the side, showing the equatorial groove; m\&n Lens culinaris seed starch with the characteristic longitudinal cleft fissure, very visible lamellae and disrupted cross with multiple arms; o\&p Babiana cedarbergensis corm starch, showing the variation in forms present in this species. Upper right is an ovoid compound with two unequal components, lower right a triangular compound with three equal components. Upper and middle left, isolated component granules. The hila are usually refractive dots and are often marked with lines or fissures that extend from the hilum to the corners of the granules. This feature is common to several members of the Iridaceae. 

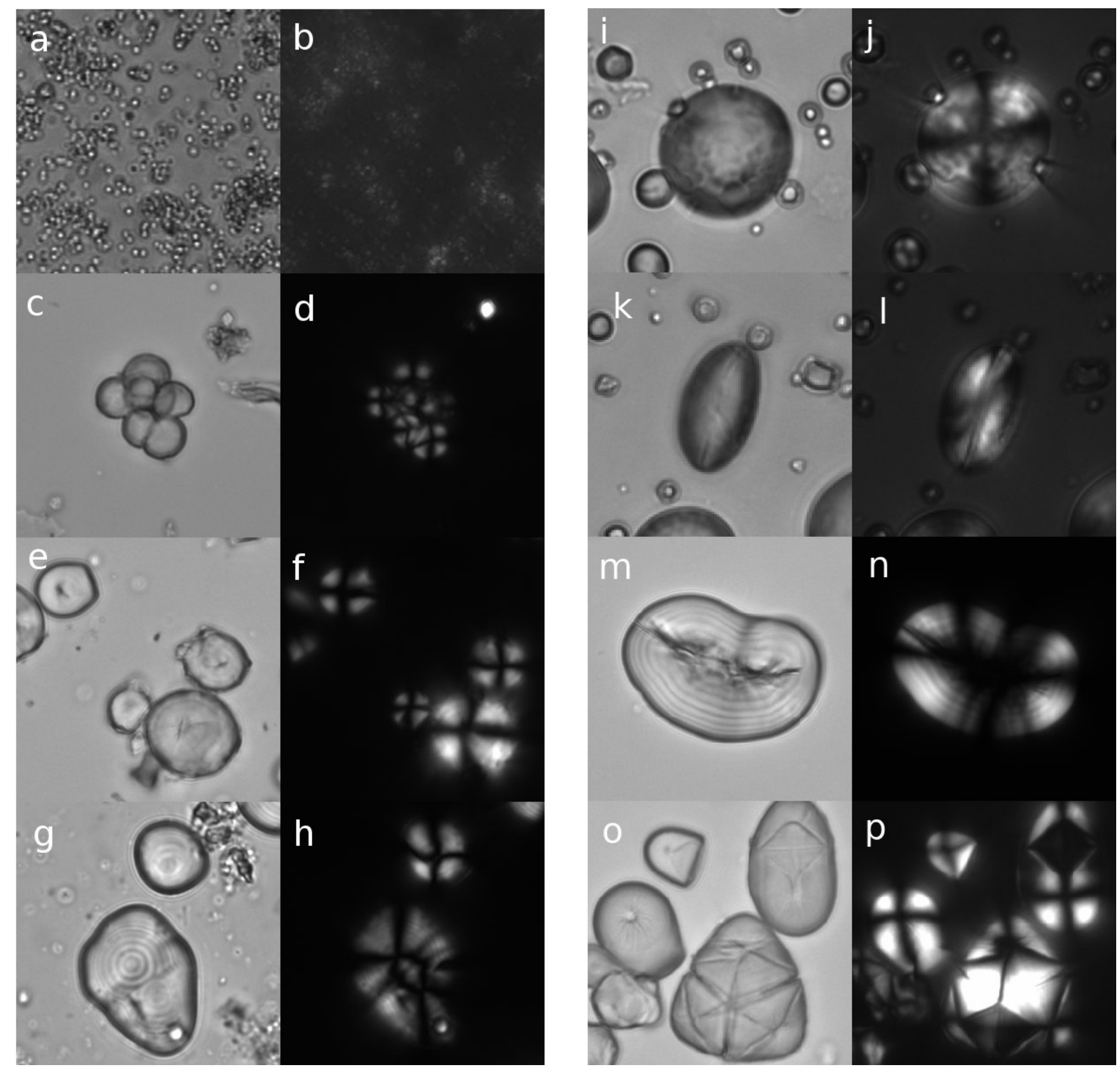

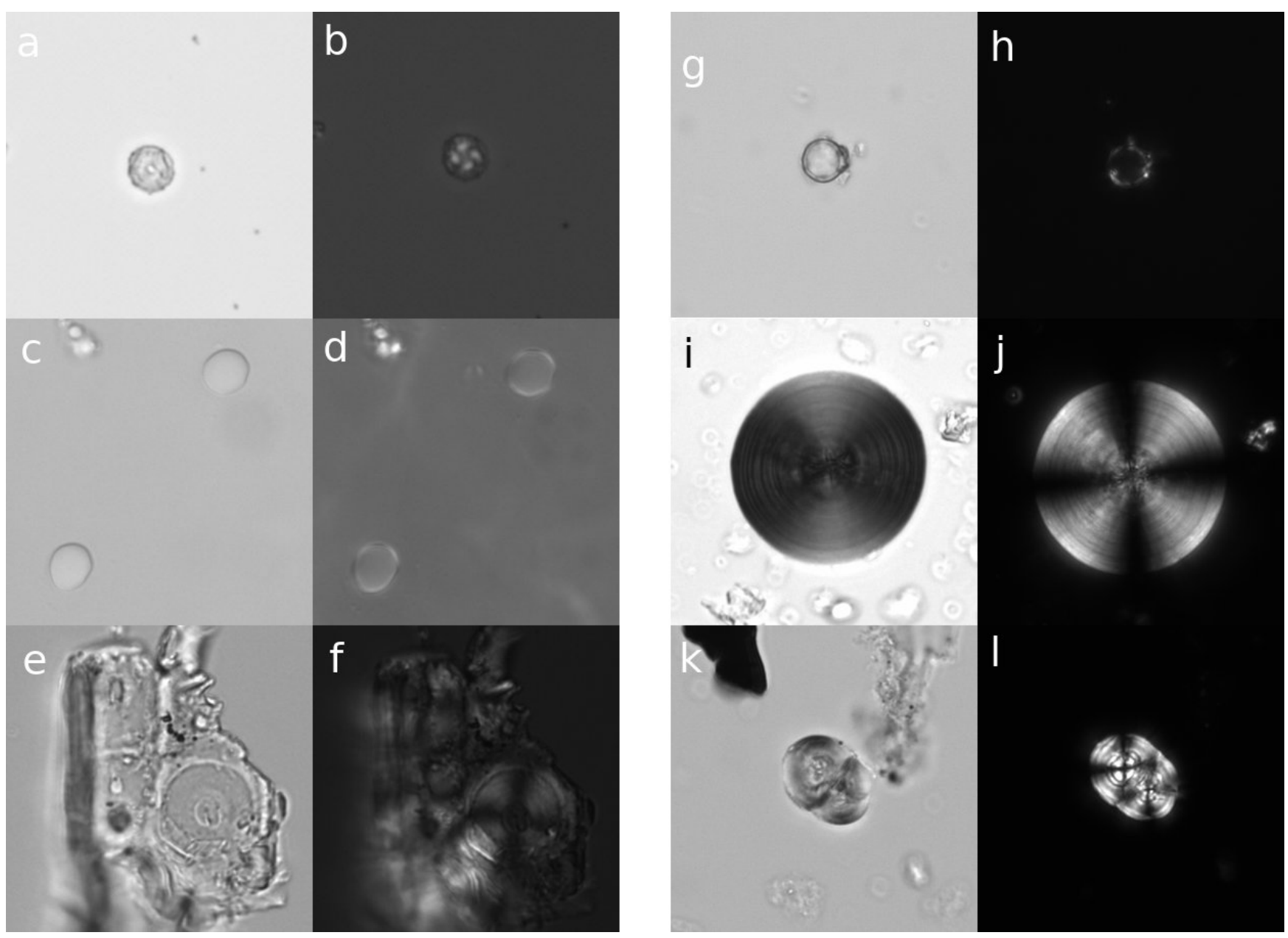

Figure 5.2: Micro remains that may be confused with starch grains.

All boxes $50 \mu \mathrm{m}$ each side. a\&b Coccoliths from a limestone cave context. Note the twisted cross; c\&d Oil bubbles from Glycine max (soy beans). Note the flat appearance and poor polarization; e\&f Fibers or cell walls from soft wood. g\&h Undecorated chrysophycean stomatocysts; i-l Spherulites of other non-starch polymers. Note the refractive quality when viewed under single-polarized light. 


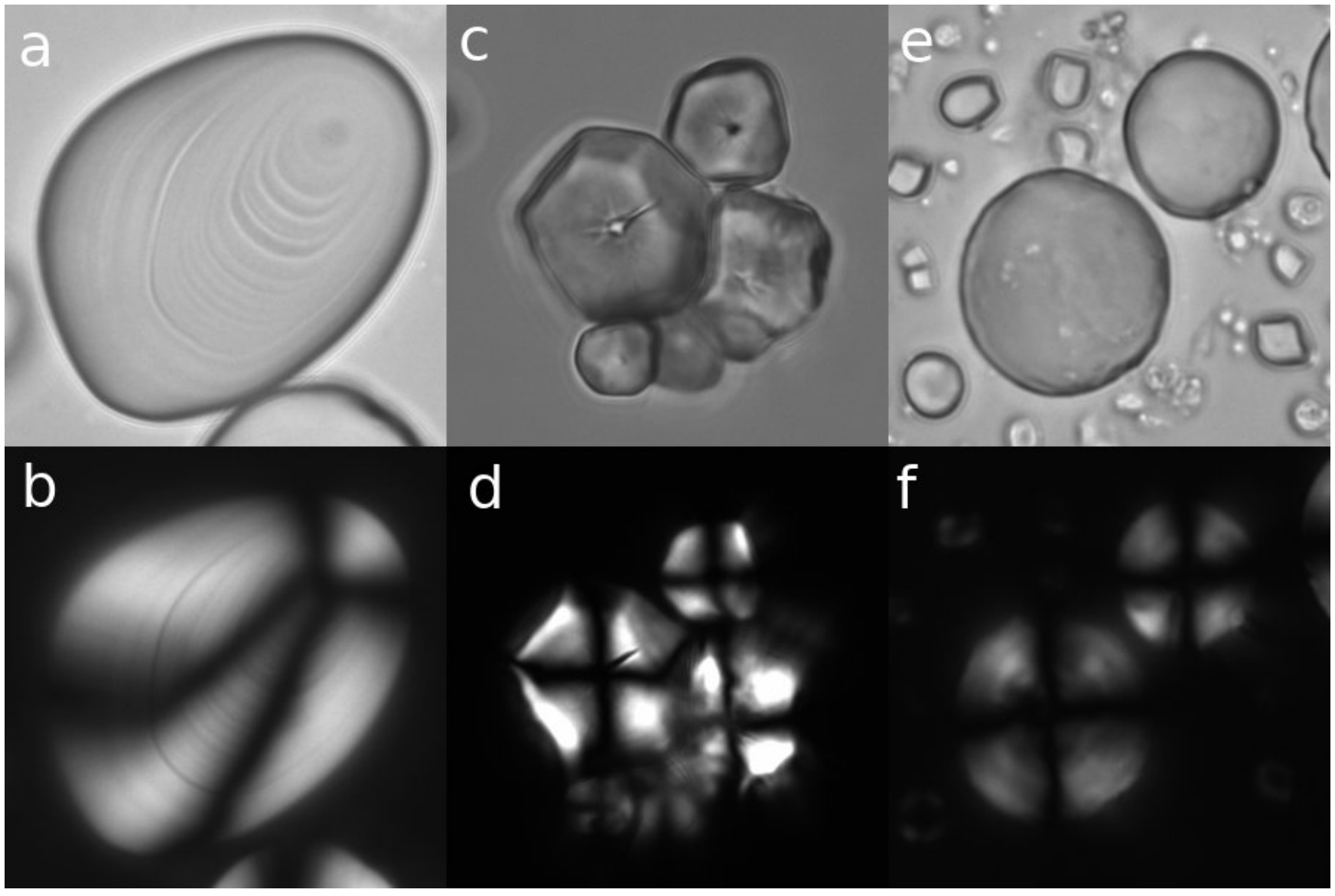

Figure 5.3: Common contaminant starches.

All boxes $50 \mu \mathrm{m}$ each side. a\&b Solanum tuberosum (potato); c\&d Zea mays (corn); e\&f Triticum aestivum (wheat). 